\title{
A LEI 10.639/2003 E O ENSINO DE GEOGRAFIA: POSSIBILIDADES DE PESQUISA E(M) ENSINO ATRAVÉS DA LITERATURA AFRICANA
}

\author{
Law 10.639/2003 and geography teaching: possibilities for research and teaching using \\ African literature
}

\author{
Rafaela Pacheco Dalbem*
}

Universidade Federal do Paraná - rafapdalbem@gmail.com.

\begin{abstract}
Recebido em 15/08/2018. Aceito para publicação em 25/08/2018.
Versão online publicada em 20/11/2018 (http://seer.ufrgs.br/paraonde)
\end{abstract}

\begin{abstract}
Resumo:
A lei 10.639, que deveria assegurar o ensino de "História da África e dos Africanos, a luta dos negros no Brasil, a cultura negra brasileira e o negro na formação da sociedade nacional, resgatando a contribuição do povo negro (...) pertinentes à História do Brasil" foi aprovada há 14 anos e, de acordo com algumas pesquisas, ainda hoje configura-se mais como uma ação individual de alguns docentes do que uma prática pedagógica adotada pelas instituições escolares. 0 trabalho consiste na apresentação de uma prática pedagógica de três anos em uma instituição particular de ensino voltada a alunos e alunas do $8^{\circ}$ ano do ensino fundamental, quando a geografia do continente africano toma corpo como unidade curricular. Aliados ao livro didático, buscamos acrescentar obras de literatura de autores africanos com o intuito não só de incentivar a leitura mas, também, transcender a formação clássica e conteudista.
\end{abstract}

Palavras-chave: Geografia Escolar; Lei 10.639/2003; Literatura Africana.

\begin{abstract}
:
Brazilian Law 10.639, which should ensure the teaching of "History of Africa and Africans, the struggle of black people in Brazil, black people culture in Brazil, and the black people in the national society formation, in order to redeem the contribution of the black people regarding to Brazil History". The law in question has been approved for 15 years and, according to some research, even today it is more an individual action from some teachers than a pedagogical practice adopted by school institutions. The present paper consists in the presentation of a three year teaching practice in a private school directed to students of the 8th grade. Allied to the textbook, we seek to add African authors' literature pieces not only intended to encourage reading, but also to transcend the classical and continuist formation.
\end{abstract}

Key-words: Scholar Geography; Law 10.639/2003, African Literature

\section{Introdução}

0 trabalho aqui apresentado faz parte da prática de três anos em uma instituição particular de ensino voltada a alunos e alunas do $8^{\mathrm{o}}$ ano do ensino fundamental, quando a geografia do continente africano - em geral - toma corpo como unidade curricular. Em paralelo ao uso do livro didático, essa prática visa a interação com autores e autoras do continente africano que possuam, de alguma forma, algum aspecto histórico-geográfico em suas obras.

Para tal, iniciaremos o trabalho com algumas reflexões sobre geografia e currículo escolar, a lei $10.639 / 2003$ e então passaremos para a proposta metodológica.

\section{Desenvolvimento}

Se por um período a geografia escolar foi baseada na capacidade de memorização e na criação de 
um sentimento de pertença nacional (junto com Língua Nacional e História), essa prática hoje mostrase datada. Tentar organizar aulas baseadas somente na exposição e voltada para um grupo de estudantes dinâmicos e cheio de energia é pedir para que a escola, cuja estrutura ainda é ultrapassada, se conforme a ser um ambiente afastado da realidade além dos muros. 0 ambiente escolar é, por si só, cheio de conflitos (o que não necessariamente significa algo ruim), e muitos desses conflitos são explicados pela falta de contextualização dos conteúdos e, ainda, a falta de inclusão de determinados grupos no currículo escolar.

Nesse sentido, as lutas do Movimento Negro Unificado que culminaram na aprovação da Lei 10.639/2003 (e posteriormente na Lei 11.645/2008) é muito importante na medida em que provoca a nossa cultura escolar, que é colonizada, a pensar em outras atrizes e atores no contexto de currículo escolar. É importante ressaltar que não queremos dizer que conhecer os aspectos que hoje estão como foco nos livros didáticos e nos currículos escolares devem ser proibidos, o que defendemos é que esses conhecimentos privilegiados há séculos sejam tirados do foco principal. Para isso, nós educadores e alfabetizadores da ciência geográfica (na verdade, qualquer área do conhecimento), devemos entender que mais do que para o mercado de trabalho, a geografia pode ajuda-lo além da escola.

Buscando atingir várias realidades e tornar o ambiente escolar mais saudável, o geógrafo $\mathrm{Dr}$ Roberto Filizola (2009) nos diz que, para estabelecer os objetivos do ensino da Geografia hoje, devemos considerar quatro aspectos de referência. Esses aspectos são: As (novas) tendências da Geografia enquanto ciência, isto é, proceder a uma reflexão epistemológica, mas em torno de uma epistemologia contemporânea; 0 mundo contemporâneo, que é marcadamente transitório, instável, desarticulado e ambivalente, portanto de uma complexidade inegável; As particularidades da sociedade brasileira, aí presente suas contradições, bem como sua diversidade étnico-cultural; As especificidades de cada segmento de ensino (Educação Infantil, Ensino Fundamental, Ensino Médio, Educação Especial, EJA), com foco voltado para o perfil (ou perfis?) de seu alunado.

Esses aspectos de referências apontados pelo autor nos dão uma visão panorâmica no sentido de onde devemos partir, no entanto, acrescentaríamos que as novas tendências epistemológicas de educação também devem ser levadas em consideração (não só apenas as de geografia). No que diz respeito ao segundo ponto do autor, o "mundo contemporâneo" acaba por recair na tecnologia e na dinamicidade das informações, em como filtrá-las e identificar as boas fontes. Ainda há a necessidade de uma instrução no sentido de como empregar a internet como ferramenta de pesquisa, mas ela está lá, presente, no cotidiano de uma parcela considerável da população escolar.

No entanto, o terceiro e o quarto ponto são de extrema relevância para uma vivência proveitosa em sala de aula, e por um motivo bem simples: há que fazer sentido aos alunos. Pensar a educação em todas as áreas do conhecimento - levando em consideração a diversidade cultural da sociedade brasileira, bem como os segmentos a que aquele conteúdo se destina, é pensar maneiras de incluir os estudantes e, principalmente, mostrar às comunidades 'não escolares' que os saberes não são tão distantes como se pensa. Esses dois pontos são importantes porque os currículos tradicionais de maneira geral não incluem outras visões senão aquelas que vieram junto com o sistema colonial. Nesse sentido, o ensino da Geografia na Educação Básica justifica-se pelas ferramentas e relações que pode proporcionar aos alunos. Ver, aprender a ser e entender seu meio são alguns dos benefícios que a ciência geográfica pode proporcionar ao grupo de estudantes e fazer com que elas e eles se sintam mais inserida(o)s no(s) contexto(s) em que habita(m).

Por isso, ressaltamos mais uma vez que a incorporação de conteúdos que promovam uma educação antirracista é de extrema importância da Lei 10639/2003 pode colaborar com isso. No que diz respeito à trabalhos acadêmicos que relacionem a geografia com a Lei 10.639/2003, encontramos tanto na forma de artigos e trabalhos de conclusão de estudos (seja como monografia, dissertação ou tese). 0 que muitos desses trabalhos possuem em comum é o corpo da referência bibliográfica, uma vez que um número considerável de trabalhos apresenta o Dr. Alecsandro (Alex) José Prudêncio Ratts (UFG), Dr. Rafael Sânzio Araújo dos Anjos (UnB) e o Dr. Renato Emerson dos Santos (FFP/UERJ).

O trabalho que destacamos de Ratts (2006/2007) foi escrito com outra geógrafa e outros geógrafos (Ana Paula Costa Rodrigues, Benjamin Pereira Vilela e Diogo Marçal Cirqueira) e é intitulado "Representações da África e da população negra nos livros didáticos de Geografia". Esse trabalho e suas respectivas conclusões foram elaborados sobre duas coleções de livros didáticos para os últimos 
anos do ensino fundamental, onde os autores e autora encontraram uma série de generalizações sobre a geografia africana.

Em um outro trabalho de Ratts (2010) "Geografia, relações étnico-raciais e educação: a dimensão espacial das políticas de ações afirmativas no ensino", o autor faz um apanhado ao redor da mítica democracia racial brasileira e faz uma sistematização da política de cotas das universidades públicas brasileiras. Ainda nesse trabalho o autor faz uma crítica ao que se consolidou como geografia crítica no Brasil, na medida em que os estudos de grupos étnicos tratam quase que exclusivamente de estudos territoriais.

Ratts utiliza o Dr Rafael Sânzio Araújo dos Anjos no seu corpo teórico através do texto "A Geografia, a África e os Negros Brasileiros", texto que também foi encontrado em vários trabalhos. Nesse trabalho toma corpo ao utilizar a cartografia para demonstrar as regiões de onde saíram as ondas de trabalhadores escravos do continente africano e onde hoje se concentram os quilombos espaços de resistência - e a população negra. 0 texto é de 2005 e o autor discorda de alguns dados das estatísticas oficiais sobre o número de negros no Brasil, números esses que começaram a aparecer depois da mudança na metodologia de pesquisa do IBGE . 0 autor ainda destaca (p.173) que os povos africanos não podem ser reduzidos à questão de povoamento e de mão de obra, mas que marcaram com força nossa formação cultural e social e que a imagem de folclorização ligada aos povos africanos deveria ser deixada de lado. Em outro texto, também de 2005, o autor assinala que a população negra é segregada dentro do sistema educacional desde a pré-escola e que isso é resultado, em partes, de inadequações metodológicas.

$\mathrm{Na}$ mesma linha de geografia que critica a ordem epistemológica vigente e também como um grande influenciador dos estudos de geografia e educação antirracista no Brasil, encontramos o professor Dr Renato Emerson dos Santos. Entre as suas contribuições gostaríamos de destacar dois textos: A Lei 10.639 e o Ensino de Geografia: construindo uma agenda de pesquisa - ação (2011) e 0 ensino de Geografia e a Lei 10.639: algumas discussões de currículo (2015);

No texto mais antigo destacado nessa pesquisa, concordamos com o autor quando ele chama a atenção para o fato de que a aprovação da lei é um momento importante, no entanto, a lei por si só não garante uma educação antirracista, uma vez que é só prescreve o que deve ser levado em consideração e a sua aplicação nem sempre leva em consideração os atores envolvidos, que aqui seriam a estrutura curricular, o livro didático, a estrutura escolar como um todo (p.8).

No outro texto destacado o autor fala especificamente sobre a lei 10639 e currículo (coisa que já vinha sinalizando em outros textos). Aqui (p. 320) o professor reforça a ideia de que o objetivo da Lei é reposicionar o negro e as relações raciais no mundo da educação, o que implica em rever todos os âmbitos do ambiente escolar e transformar a maneira como as escolas executam a coordenação das relações raciais no seu cotidiano. 0 autor cita Grosfoguel na página 322 ao afirmar que, no sistema capitalista - que acaba influenciando a educação - temos um conjunto de dominação e exploração baseado em diversas hierarquias (sexual, locacional, de gênero, espiritual, etc.).

Um exercício de sistematização semelhante foi encontrado na obra do pedagogo galego Jurjo Torres Santomé (2013). 0 autor defende que a cultura escolar possui vozes mais fortes do que outras. Em uma tabela do seu livro "Currículo, escola e justiça social: o cavalo de Troia da educação" (p. 241) o autor evidencia que as vozes mais fortes dentro da cultura escolar são aquelas do mundo masculino, adulto, sãs, heterossexuais, com profissões de prestígio, urbanas, de estados e nações poderosas ocidentais, brancas e católicas. Em contrapartida, as vozes que seriam todas as categorias antônimas àquelas citadas anteriormente, configuram as vozes ausentes da cultura escolar.

Essas vozes ausentes, que aparecem nas lutas dos movimentos sociais, estão cansadas de serem silenciadas, estão cansadas da injustiça cognitiva a qual foram subjugadas ao longo dos anos. Nesse mesmo sentido, o sociólogo mineiro e doutor em educação Miguel Gonzáles Arroyo infere que, para entender os sentidos da chegada às escolas dos setores populares teremos de (...) lembrar a longa história de ausências, os processos de ocultamento desses coletivos em nossa história. Foram ignorados, não reconhecidos, tratados como inferiores, não existentes. (2011, p. 156). É aqui que entram as comunidades africanas, afrodescendentes e indígenas brasileiras, há muito silenciadas no currículo escolar.

A escolarização é um direito, em tese, assegurado na constituição e os conteúdos ali passados

ParaOnde!?, Porto Alegre, v.10, n.2, p.149-155, 2018. Edição Especial com artigos publicados originalmente na XII ENANPEGE http://seer.ufrgs.br/paraonde 
são encarados como legítimos dentro da sociedade de maneira geral. Sendo assim, privilegiar apenas um ponto de vista, um lado da história, é cruel. Nós já apresentamos as ponderações de Filizola nas páginas anteriores, mas também gostaríamos de destacar as ideias de Pierre Bourdieu (sociólogo francês que também figura nas indicações bibliográficas do Prof Dr Renato Emerson dos Santos).

Pierre Bourdieu (2007) apontou o sistema e o processo de escolarização, como um processo que não privilegia a educação e a vivência das classes menos favorecidas, ele ainda coloca que "é provavelmente por um efeito de inércia cultural que continuamos tomando o sistema escolar como um fator de mobilidade social, segundo a ideologia da 'escola libertadora'” (p. 39).

Não concordamos em todos os aspectos com o autor, mas, como dito anteriormente, concordamos que o conhecimento presente no sistema escolar está distante da maior parte da população e que, no fim das contas, não equipara conhecimentos e cultura porque os que se reconhecem nos currículos acabam em posição de destaque.

\section{Proposta de prática pedagógica}

O ponto de partida para o início dessa prática, se deu principalmente em dois motivos: I. a urgência em trabalhar em sala um aluno que está no currículo escolar, mas não está, necessariamente, entre as disciplinas que compõe a grade dos cursos de licenciatura em geografia; e II. a qualidade do material adotado na instituição de trabalho. Juntamos a isso o imaginário popular sobre o continente africano e tínhamos em nossas mãos um grupo de estudantes que pensa em um território com características uniformes: a da pobreza, da economia fraca, da fome, da AIDS, das guerras civis, de safáris e de animações dos estúdios Pixar.

O livro adotado pela instituição e que motivou a desenvolver essa prática foi o Observatório de Geografia - 8o Ano - Fronteiras e Nações, da autoria de Regina Araujo, Raul Borges Guimarães e Ângela Corrêa Silva. Nessa obra, as autoras e o autor afirmam que os africanos foram escravizados e trazidos para a América Central porque não existia população local para trabalhar nas plantações e que, por isso, há um grande contingente de negros nesses territórios. Em momento algum é levantado um posicionamento crítico sobre o processo colonial e, no máximo, coloca-se a pobreza de alguns territórios como consequência do processo colonial (sem questionar o processo em si). Com esses problemas em vista, passei a procurar alternativas para suprir essa lacuna e, para isso, a inclusão de diferentes linguagens para o estudo desses territórios mostrou-se como uma possibilidade interessante.

Por indicação de uma amiga, conheci um artigo do site Outras Palavras que provocava as/os leitores a pensar o BRICS também sob uma perspectiva cultural e citava a literatura como sendo o caminho. $\mathrm{O}$ autor do texto (Renato Xavier dos Santos) coloca que a literatura do Brasil nos é bem conhecida uma vez que se constitui na literatura nacional, também indica que não é raro ouvirmos falar de literatura russa (vide Dostoievski), no entanto, as literaturas chinesa, indiana e sul-africana ainda são desconhecidas da maioria. Nesse contexto o autor apresenta Nadine Gordimer (escritora sulafricana) e ao pesquisar sobre ela percebi que sua obra e ativismo girava em torno da luta contra o apartheid e, a partir daí, comecei a procurar e montar um mosaico com autoras e autores do continente africano para tentar suprir as minhas dificuldades de trabalhar o conteúdo.

Embora haja a indicação de livros, optamos também por indicar alguns vídeos disponíveis no YouTube para que o grupo de estudantes possa ter a oportunidade de personificar essas pessoas. Gostaria de deixar claro que, devido ao volume de trabalho e mesmo a profundidade de algumas das obras - com um grau de exigência que a leitura da obra completa inferiria na(o)s estudantes dessa idade-, esse trabalho se trata de uma aproximação/sensibilização a respeito da literatura do continente africano, e não um estudo literário em si. No entanto, dentro do grupo que participou desse trabalho até hoje, percebemos que os livros destacados na tabela que será apresentada a seguir são os que acabam capturando a atenção e os integrantes dos grupos acabam lendo a obra toda.

Para embasar a forma de utilizar essas obras em sala e incentivar a participação e a partilha com o grupo por parte daquelas(es) que leram a obra toda, nos baseamos nos escritos do geógrafo canadense Marc Brosseau. Em um capítulo intitulado "O romance, outro sujeito para a Geografia" (Le Roman: um autre sujet pour la géographie"), o autor defende que a utilização dos romances e da 
literatura em geral dentro da geografia deve ir além do sentido instrumental e não devemos encaixá-lo em fichas de leitura pois isso implicaria na perda da sua riqueza para que o mesmo acomodasse as necessidades de uma linguagem das ciências humanas. (p. 80-82). 0 autor defende, portanto, o diálogo entre a literatura e a geografia (p. 116). Nesse sentido, o diálogo entre as áreas configura-se na alternativa mais rica de interação e, por isso, o trabalho buscou ter esse objetivo em mente.

Corroborando com as ideias de Brosseau, as geógrafas Nídia Nacib Pontuschka, Tomoko Iyda Paganelli e Núria Hanglei Cacete (2007), sobre trabalhar geografia e literatura, destacam que trabalhar as informações como geralmente aparecem nos livros didáticos de geografia, implica em passar uma informação 'seca' (p. 235) mas que, ao ler o livro, a/o aluna/o e a/o docente podem perceber como vários aspectos culturais daquele povo. Ainda, as autoras colocam que (p.236) a literatura é fonte de prazer, mas não é só isso. É igualmente modo de conhecer o mundo.

Há que se fazer uma ressalva, porém: o público-alvo dessa prática pedagógica tem entre 12 e 13 anos de idade, o que implica na necessidade de uma diretividade maior por parte do professor (que, inevitavelmente, em alguns momentos, pode vir a ser interpretada como uma instrumentalização da obra em questão). No entanto, nenhuma das obras é usada como um manual paradidático.

Outros autores estão em estudo nesse momento, como Wole Soyinka (também nigeriano) e Futhi Ntshingila (também da África do Sul), e estou procurando obras de outros países, embora em muitos momentos o problema maior é a tradução.

0 "aspecto de referência" configura-se geralmente em um tópico que aparece no livro didático, e a intenção é mostrar que esses eventos aparecem em obras artísticas e podem proporcionar outras visões (em algumas obras, a visão daquele que viveu). Por exemplo, fala-se muito do extremismo islâmico mas nunca do católico, e a obra da Chimamanda Adichie mostra que isso também pode ocorrer; Fala-se das crianças soldado na Guerra de Serra Leoa, mas Ishmael Beah foi uma dessas crianças e relata em primeira pessoa. Chinua Achebe critica a imposição da cultura britânica com tanta elegância que em alguns momentos gera dúvidas.

Abaixo está a lista de autoras/autores e livros trabalhados nesse ano de 2017:

\begin{tabular}{|c|c|c|c|}
\hline AUTOR(A) & PAÍS DE ORIGEM & OBRA INDICADA & ASPECTO DE REFERÊNCIA \\
\hline Ayaan Hirsi Ali & Somália & $\begin{array}{l}\text { Infiel } \\
\text { - vídeo no youtube "Ayaan Hirsi } \\
\text { Ali (legendado) - Discurso na } \\
\text { Universidade de Wisconsin - } \\
\text { Série Palestras }\end{array}$ & $\begin{array}{l}\text { Extremismo religioso, mulheres } \\
\text { e islamismo }\end{array}$ \\
\hline $\begin{array}{l}\text { Chimamanda Ngozi } \\
\text { Adichie }\end{array}$ & Nigéria & Hibisco Roxo & $\begin{array}{l}\text { Extremismo religioso, mulheres } \\
\text { e catolicismo }\end{array}$ \\
\hline Chinua Achebe & Nigéria & A flecha de Deus & $\begin{array}{l}\text { Degradação da cultura nigeriana } \\
\text { pela coexistência com o } \\
\text { colonizador }\end{array}$ \\
\hline Immaculée Ilibagiza & Ruanda & $\begin{array}{l}\text { Sobrevivi para Contar - O Poder da } \\
\text { Fé me Salvou de um Massacre } \\
\text { - vídeo no youtube "Immaculée } \\
\text { Ilibagiza a mulher que sobreviveu } \\
\text { para contar" }\end{array}$ & Genocídio em Ruanda de 1994 \\
\hline Ishmael Beah & Serra Leoa & $\begin{array}{l}\text { Muito longe de casa: memórias de } \\
\text { um menino soldado } \\
\text { - vídeo no youtube "eye to eye: } \\
\text { Ishmael Beah (CBS News( } \\
\text { (legendado em português) }\end{array}$ & Guerra Civil de Serra Leoa \\
\hline Mia Couto & Moçambique & $\begin{array}{l}\text { Terra Sonâmbula } \\
\text { - vídeo no youtube "Mia Couto - } \\
05 / 11 / 2012 "\end{array}$ & $\begin{array}{l}\text { Guerra Civil Moçambicana e } \\
\text { dimensão mítica da cultura } \\
\text { africana }\end{array}$ \\
\hline Nadine Gordimer & África do Sul & $\begin{array}{l}\text { O Conservador } \\
\text { - vídeo no youtube "Nadine } \\
\text { Gordimer }-08 / 07 / 2007 "\end{array}$ & Apartheid \\
\hline Ondjaki & Angola & $\begin{array}{l}\text { Bom dia camaradas } \\
\text { - vídeo no youtube "Roda Viva - } \\
\text { Ondjaki - } 15 / 01 / 2007 \text { " }\end{array}$ & Angola pós-independência \\
\hline
\end{tabular}




\begin{tabular}{|l|l|l|l|}
\hline & Moçambique & $\begin{array}{l}\text { Ventos do Apocalipse } \\
- \text { vídeo no youtube “Paulina } \\
\text { Chiziane A Páginas Tantas" } \\
\text { (português de Portugal) }\end{array}$ & Moçambique pós Guerra Civil \\
\hline Pepetela & Angola & $\begin{array}{l}\text { Mayombe } \\
- \text { vídeo no youtube “Leituras| } \\
\text { Mayombe" }\end{array}$ & $\begin{array}{l}\text { Angola pré-independência } \\
\text { (Guerra Angolana) }\end{array}$ \\
\hline
\end{tabular}

Para a elaboração do trabalho, os alunos serão divididos em dez grupos para que os dez autores sejam trabalhados em todas as turmas. Cada um dos grupos deverá elaborar um documento (para ser entregue à professora) que deve conter pelo menos os pontos listados abaixo:

1. Foto e nome do(a) autor(a);

2. País de origem (com mapa de localização) e país onde mora atualmente (também com mapa de localização - em caso de autores que mudaram de país, o grupo deve informar os motivos da mudança);

3. Breve biografia (formação acadêmica - se tiver -, obras publicadas, área em que dedica seus estudos, curiosidades da vida profissional/pessoal, ligação com a política de seus países, local e causa de falecimento, etc.)

4. $\quad$ Nome da obra indicada com breve resumo;

5. Uma pesquisa de no mínimo duas páginas sobre o "aspecto de referência" destacado na tabela acima;

6. Bibliografia - sites de referência

Após a entrega do trabalho, os grupos apresentam seus autores para a turma. Essa apresentação pode ser em powerpoint ou prezi e deve conter todos os dados pesquisados. Todas e todos integrantes do grupo devem falar e cada grupo terá no mínimo 15 minutos de apresentação.

\section{Considerações Finais}

Embora muito se discuta em reuniões pedagógicas sobre novas formas de aprender e ensinar a Geografia, a prática ainda se mostra tradicional em muitas escolas/salas de aula. A proposta de trabalho com os livros de autoras e autores do continente africano não é somente uma forma diferente de nos aproximarmos de um conteúdo que está no currículo programático escolar, mas também uma prática intencional de suscitar a curiosidade e sensibilidade do aluno ao entrar em contato com outras formas de se olhar para um lugar/paisagem/território. A intencionalidade maior é, sim, a da sensibilização e fazer com que o grupo de estudantes tome contato com uma gama de escritoras e escritores que fuja da clássica literatura levada para dentro de sala de aula (masculina, branca e de países ricos).

Entendemos que nem todas as instituições de ensino poderão dispor tantas obras, mas essa proposta pode ser adaptada para quantas obras a/o educador(a) julgar possível ou, até mesmo, que a/o própria(o) educador(a) possa entrar em contato com as obras e, nas palavras de Brosseau, melhorar a sua própria geografia e provocar seu alunado.

A prática descrita acima é uma aproximação menos óbvia, uma vez que nenhuma das obras é considerada como didática ou paradidática e a escolha das mesmas, assim como o decorrer da prática em si, demonstra que no processo de educação geográfica nenhuma linguagem deve ser excluída desse processo de sensibilização e quanto mais possível devem ser incluídas para um 'melhor olhar' do espaço.

\section{Referências}

ANJOS, Rafael Sanzio A. dos. A Geografia, a África e os negros brasileiros. In: MUNANGA, Kabengele (Org.). Superando o racismo na escola. Brasília: Ministério da Educação, 2005, v. 1, p. 173-184.

ANJOS, Rafael Sanzio A. dos. A África, a educação brasileira e a geografia. In: SECAD/MEC (Org.). Educação antirracista: caminhos abertos pela Lei Federal no 10.639/2003. Brasília-DF: 
MEC/BID/UNESCO, 2005, v. 1, p. 167-178.

ARAÚJO, Regina; SILVA, Ângela Corrêa da; GUIMARÃES, Raul Borges. Observatório de Geografia: fronteiras e nações. $1^{\mathfrak{a}}$ ed. Editora Moderna, $264 \mathrm{p}$.

ARROYO, Miguel G. Currículo, território em disputa. 2ª ed. Petrópolis, RJ. Vozes, 2011. 376p.

BOURDIEU, Pierre. A escola conservadora: as desigualdades frente à escola e à cultura. In: NOGUEIRA, Maria Alice \& CATANI, Afrânio (org). Escritos de educação. 9a ed. Petrópolis, RJ: Vozes, 2007. p. 39-64.

BROSSEAU, Marc. Des romans-géographes. Paris, L'Harmattan, (coll. GÉographie et cultures), 246p.

FILIZOLA, Roberto. Didática da Geografia: proposições metodológicas e conteúdos entrelaçados com a avaliação. Curitiba: Base Editorial, 2009, 120p.

PONTUSCHKA, N. N., PAGANELLI, T. I. \& CACETE, N. H. Para ensinar e aprender Geografia. São Paulo: Cortez, 2007, 1ํㅡㄹ edição, 383 p.

RATTS, Alecsandro (Alex). Geografia, relações étnico-raciais e educação: a dimensão espacial das políticas de ações afirmativas no ensino. Terra Livre. vol. 1, n. 34, p. 125-140, jan-jun, 2010.

RATTS, Alecsandro (Alex) J. P. et al. Representações da África e da população negra nos livros didáticos de Geografia. Revista da Casa da Geografia de Sobral, Sobral, v. 8/9, n. 1, p. 45-59, $2006 / 2007$.

SANTOMÉ, Jurjo Torres. Currículo escolar e justiça social: o cavalo de Troia da educação. Porto Alegre: Penso, 2013, 335p.

SANTOS, Renato Emerson dos. A Lei 10.639/03 e o Ensino de Geografia: Construindo uma agenda de pesquisa-ação. Tamoios, Ano VII, nำ1, 2011, 4-23.

SANTOS, Renato Emerson Nascimento dos. 0 ensino de geografia e a Lei 10.639: algumas discussões de currículo. In: Ana Cláudia Ramos Sacramento; Charlles da França Antunes; Manoel Martins de Santanna Filho. (Org.). Ensino de geografia: produção do espaço e processos formativos. 1ed.Rio de Janeiro: Consequência/FAPERJ, 2015, v. 1, p. 317-339 